\title{
CIÊNCIAS HUMANAS: INSTITUCIONALIZAÇÃO E CRISE DE INTERESSE
}

\section{THE HUMANITIES: INSTITUTIONALIZATION AND CRISIS OF INTEREST}

Pedro Dolabela Chagas ${ }^{1}$

RESUMO: a sensação de "crise" como resultante da percepção do pouco interesse da esfera pública e do alunado pelas humanidades. Discussão sobre causas externas e internas do desinteresse: problemas decorrentes da mudança dos gostos e predisposições do público e outros relativos a práticas de pesquisa e de ensino. Sugestão de alternativas de ação, envolvendo discussões sobre 1) a extensão real da diminuição da visibilidade das humanidades no debate público; 2) as condições de avaliação da sua influência; 3) a relação entre a fundamentação epistemológica do conhecimento e o seu poder de influência; 4) a autonomia da pesquisa e o seu potencial de comunicabilidade em larga escala.

PALAVRAS-CHAVE: Ciências humanas: Ensino. Pesquisa. Epistemologia. Relevância social.

ABSTRACT: the sense of "crisis" as resulting from the perception of the public sphere's and the student body's diminishing interest in the Humanities. Discussion of external and internal causes of that lack of interest: problems arising from changes in the public's tastes and dispositions and from current research and teaching practices. Suggestion of practical courses of action through the discussion of 1) the real extent of the lowering visibility of the Humanities in the public debate; 2) the conditions of evaluation of their influence; 3) the relation between the epistemological foundations of knowledge and its power of influence; 4) the autonomy of research and its large-scale communicative potential.

KEYWORDS: The Humanities: Teaching. Research. Epistemology. Social relevance.

\footnotetext{
${ }^{1}$ Universidade Federal do Paraná - UFPR.
} 


\section{CIÊNCIAS HUMANAS: INSTITUCIONALIZAÇÃO E CRISE DE INTERESSE}

"Crise das humanidades": o tema sempre retorna. Mesmo que as nossas disciplinas vivam situações distintas e que problemas localizados não sirvam, sem mais, como exemplificação de problemas comuns - eu assumo de saída o viés colocado pela minha experiência na filosofia e nos estudos literários -, a generalização permanece: vivemos há tempos o incômodo causado pelo desinteresse do alunado por carreiras que prometem baixa remuneração e status social, e pelo desinteresse da "esfera pública" pela pouca "utilidade" do nosso trabalho. É uma crise do interesse, portanto, e sob esse ângulo discutiremo-la aqui. Como toda crise, ela é motivada por problemas externos e internos ao sistema, havendo elementos que os seus agentes podem controlar nalguma medida e outros sobre os quais eles têm pouco poder de ação, ficando limitados a observar os seus próprios padrões de reação. No nosso caso, a distribuição interna e externa das causas deveria deslegitimar a tautologia que costuma transparecer nas discussões sobre o desinteresse pelas humanidades: enquanto os desinteressados qualificam-no como mera reação àquilo que não tem, em si, interesse algum, outros creditam-no à "ignorância", à "alienação", ao "pragmatismo" dominantes, sugerindo que a importância do nosso trabalho seria comprovada justamente pelo antagonismo que lhes manifestam as esferas de produção... Tais caricaturas não ajudam.

Há uma crise em curso, provavelmente várias delas, e o desinteresse de fato existe mas ao invés de apenas "criticá-lo", é mais produtivo tentar compreendê-lo sob um olhar simultaneamente interno e externo à perspectiva do professor-pesquisador, imaginando soluções que estejam ao nosso alcance. Crises impõem a autocrítica e a imaginação criadora: a convicção de fundo deste artigo é que, se o nosso poder de intervenção para além da academia é pequeno, pensar a "arrumação da casa" é o que há de mais realista a fazer. Nas páginas seguintes, os focos serão o ensino e a pesquisa: na perspectiva "externa" à nossa inscrição profissional incluirei aquela do aluno de graduação, em seus estágios iniciais de formação (quando ele ainda não está mobilizado pelo ethos acadêmico); entre as nossas disciplinas, incluirei a economia, a arquitetura e o urbanismo, as artes, a geografia, a ciência da informação - "híbridas", entre elas e o "núcleo duro" das humanidades (a história, a filosofia, a literatura, as ciências sociais...) não existem fronteiras consistentes. No mais, faço uma ressalva: não proponho questionar, aqui, o mérito ou a honestidade do trabalho intelectual, mas sim a formatação das nossas instituições, que - ao menos é a minha 
impressão - podam mais do que potencializam a emergência da inovação e da surpresa, dificultando a lida com os problemas em curso. Soluções à vista? Não sei, talvez apenas a proposição de diagnósticos - o que pode não ser pouco, afinal.

Arriscar um olhar ao mesmo tempo interno e externo à perspectiva do professorpesquisador é tentar captar a maneira o público nos observa, sem pré-julgar os seus julgamentos. Um clichê comum é o respeito quase reverente do "senso comum" pela "erudição" do humanista, associado à sensação de aquilo que fazemos não tem real utilidade, e por isso carece de importância: são clichês, eu sei, mas estamos de fato preparados para afirmarmo-nos como coletividade contra esse tipo de percepção? Que argumentos farão sentido para interlocutores que conhecemos tão pouco?

Talvez a pergunta seja excessivamente dramática. No Brasil, os cursos de pósgraduação nas humanidades só fazem crescer (ainda que por razões alheias ao potencial de absorção do mercado de trabalho); jornais de circulação nacional e programas de TV por assinatura diariamente convidam intelectuais para debaterem assuntos de amplo interesse; se ainda assim o nosso público é pequeno, acredito que entre nós a visibilidade do intelectual nunca foi substancialmente maior. Se acrescentarmos que boa parte do ativismo político e do debate nas redes sociais é conduzida por agentes formados pelas ciências humanas, é difícil acusar uma diminuição objetiva da presença das humanidades na esfera pública: que poucos intelectuais de grande presença (e eles sempre foram poucos) tenham dado lugar a inúmeros intelectuais de visibilidade capilarizada pelas redes de informação disponíveis, isso revela mudanças na participação no debate e na produção de consensos, mas não uma piora inconteste. $\mathrm{O}$ jogo mudou a ponto de tornar-se irreconhecível para o observador de trinta anos atrás: em escala global, a década de 1960 trouxe a última geração de intelectuais que se tornaria referência para o pensamento posterior (Foucault, Chomski, Habermas, Deleuze - a lista segue...); em contraste, na condição de rebentos da enorme expansão do sistema universitário a partir dos anos 70, os intelectuais vivem hoje num estado de relativa discrição - inúmeros bispos, raríssimos papas. Esta é a tendência: somos pequenos porque somos muitos; onde muitos falam, poucos são ouvidos. A isso soma-se a ascensão do especialista, cuja visibilidade se pauta, como não poderia deixar de ser, pela contribuição à sua área de especialização: enquanto o "grande intelectual público" abordava assuntos de todo tipo, hoje as figuras de ambição semelhante (Zizek, Agamben, Sloterdijk...) subsistem como formadoras de opinião (ou "polemistas"), sem grande influência sobre a pesquisa empírica - cuja validação pressupõe o domínio minucioso da matéria tratada.

Seja como for, basta folhear a "Folha de São Paulo", por exemplo, para encontrarmos artigos vários de colegas brasileiros e estrangeiros: se esta é a "esfera pública" que nos resta, parece que algum fôlego nós ainda temos. É menos do que gostaríamos que fosse e é menos do que já foi, mas lembremos que a "Folha" minguou como um todo: o futuro da mídia-jornal é incerto, vide o fechamento recente do "Jornal do Brasil"... Decerto ali a redução do espaço das humanidades não foi uniforme: se artigos ligados à arte e à ciência aparecem em menor número, aqueles mais diretamente ligados à vida prática - à economia, à política, à psicologia... - mantêm-se em evidência: a expectativa da remissão do pensamento a temas pertinentes à lida cotidiana conseguiu impor-se. Este ponto é importante. Ao enfrentarmos o problema do desinteresse, devemos compreender aquilo que está em jogo aqui: ubíqua entre os jovens universitários e a opinião pública, a expectativa da "serventia" ou da "utilidade" do conhecimento tende a ser ridicularizada pelo humanista; mas queiramos ou não, a nossa ambição de presença e influência é espelhada na expectativa quanto à aplicabilidade das nossas contribuições. Sabemos que as humanidades podem prestar-se a isso: pelo menos era algo implícito na vontade de intervenção nos modos contemporâneos (na formatação das instituições, na concepção do poder, nas relações humanas, na imaginação simbólica, nas crenças coletivas, nos padrões de comportamento) de Platão, Agostinho, 
Rousseau, Marx, Foucault... A crítica à utilidade é relativamente recente, coincidindo com a virtual abdicação pela filosofia à função de orientação da vida pessoal e coletiva e a sua reclusão progressiva ao debate especializado. O processo foi similar na literatura: até meados do século XIX, todo escritor queria fazer sucesso de público (e talvez influenciá-lo intimamente), mas a certa altura o jogo se inverteu: alguns dos autores hoje mais canonizados passaram a escrever contra as expectativas do grande público em nome de valores estéticos, morais e políticos compartilhados por uma minoria. Se porções tão qualificadas do círculo intelectual passaram a menosprezar desse modo o "senso comum", como elas poderiam manter com ele um diálogo produtivo? A pergunta é revelante, pois as humanidades parecem cindidas entre a vocação "crítica" a vocação "científica": a "crítica", com o seu tom moralizante (em Platão, Agostinho, Rousseau, Marx, Foucault - e em Zizek, Agamben, Sloterdjik...), pressupõe uma retórica da persuasão cuja influência em larga escala demandaria a predisposição à comunicação aberta, algo que muitos intelectuais, porém, tendem a rejeitar como "didatismo" ou "populismo"; por sua vez, a função "científica" pressupõe o comprometimento com a produção de resultados verificáveis, do qual ela extrai a confiabilidade sustentadora da sua ambição à influência. Mas o que somos nós, "críticos" ou "cientistas"? A partir de que posição buscamos legitimar a nossa produção de saber e, consequentemente, a nossa participação no debate público? Acredito que aprenderemos algo sobre os limites da nossa visibilidade se respondermos a tais perguntas mediante uma admissão aporética do critério da utilidade, conferindo-lhe a legitimidade que ele não costuma receber entre nós, para questioná-lo, em contrapartida, a partir de argumentos fundamentados não por conjuntos localizados de crenças (em suas implicações sobre a nossa auto-definição como coletividade), mas pela observação das nossas condições de produção de conhecimento. Com isso, ao invés de menosprezarmos a acusação de "inutilidade" mediante a idealização da nossa própria "importância", poderíamos afirmar as nossas possibilidades mediante o reconhecimento das limitações inerentes ao estudo das nossas matérias - cuja importância cotidiana, afinal, deveria ser fácil de demonstrar...

Desnecessário dizer, o elemento interpretativo e os conflitos de valor inerentes à discussão filosófica e à análise de fenômenos passados, determinados por ações conscientes e inconscientes de indivíduos que jamais conheceremos em primeira mão e cujas conseqüências práticas são dificilmente quantificáveis, é desnecessário dizer que a matéria das humanidades está aquém da precisão, da previsão, da reprodução controlada do experimento que associamos às ciências da natureza. Mas algum grau de objetividade a nossa produção deve comportar - no mínimo, os pensadores de maior impacto no século XX souberam apresentar o real de modo convincente, organizando os seus elementos de maneira filosoficamente bem argumentada e epistemologicamente consistente, e assim renovando a sua interpretação. Esta aparência de verdade não pode durar para sempre: as teorias se desgastam, seja por razões externas a elas (novos dados que as colocam em suspenso), seja pelo seu desgaste interno (como ocorreu com o estruturalismo, que praticamente se esgotou como proposição de pesquisa). Isso não leva necessariamente à obsolescência, mas tampouco deixará de levar caso não se faça da crise um momento de "destruição criativa": se há uma crise de interesse em andamento, ela pode estar ocorrendo porque certos temas perderam popularidade, ou porque expectativas quanto à função prática do conhecimento não são atendidas, ou porque os nossos modos de endereçamento a objetos que preservam interesse não parecem interessantes a quem deveriam - e a discussão sobre estas possibilidades será mais fértil se integrarmos a reflexão sobre a participação das humanidades no debate público à reflexão sobre as nossas condições institucionais e epistemológicas de produção de conhecimento.

Em relação à primeira causa acima, parecemos de fato condenados a uma posição reativa: se muitos dos nossos objetos despertam o interesse de uma pequena parte do público, isso é algo que, a rigor, nós não podemos controlar; alguma influência nós podemos tentar 
exercer, mas as perspectivas não são quantitativamente promissoras. Mas o caso é que, mesmo que eu acredite que a nossa sociedade tem algo a perder com a diminuição da leitura de poesia, não basta limitar-me a reclamar deste estado de coisas, responsabilizando o mundo pela minha tristeza; quer queiramos ou não, a diminuição do interesse pelos nossos objetos de eleição nos obriga a admitir a circunscrição acadêmica do nosso trabalho, ou então a buscar objetos de maior apelo. Esta segunda opção não é necessariamente populista: ela pode simplesmente derivar da constatação de que os nossos objetos se integram a campos maiores, que seguem, sim, despertando interesse. Por exemplo, ainda que o romance seja pouco lido o interesse pela narrativa ficcional continua sólido, mesmo que as mídias de maior apelo sejam audiovisuais: em muitos casos, "buscar objetos de maior apelo" pode envolver apenas um esforço de remissão sistemática a temas de maior interesse, sob toda sorte de conexões possíveis. De modo semelhante, a outra reação mencionada - reconhecer a vocação acadêmica do nosso trabalho - não implica resignação: pelo contrário, ela apresenta um viés produtivo, ao pressupor a afirmação "weberiana" da autonomia da ciência na determinação dos seus objetos de investigação - a ciência estuda aquilo que ela mesma julga digno de ser estudado; que outra instância teria competência para orientá-la? Esta autonomia pode soar ilegítima para o observador externo: é como se gozássemos de uma prerrogativa negada a outros campos de atividade profissional, obrigados, como eles costumam ser, a atender a interesses alheios. A isso respondemos que o conhecimento tem valor imanente, à revelia da sua eventual utilidade; que ele torna o mundo mais imaginativo e menos propenso ao dogmatismo, mesmo que seja difícil identificar tais resultados concretamente; que a sociedade que preserva um lugar para a pesquisa descompromissada com a urgência das demandas materiais e políticas será intelectualmente mais diversificada e propensa à emergência do inesperado. O que importa é notar que nestes dois caminhos sugeridos - entre outros possíveis - a produtividade do trabalho acadêmico está assegurada, cabendo ao pesquisador apenas tentar antecipar as implicações das suas escolhas para a extensão do interesse que elas despertarão.

Quanto à segunda causa possível do desinteresse - a expectativa do público quanto à efetividade prática do saber -, ela comporta algo de ingênuo ou de exagerado: poucos autores alcançaram maior influência sobre "corações e mentes" no século XX que humanistas como Marx e Freud, assim como as visões gestadas nas ciências humanas continuam circulando caoticamente num montante que contribui para informar a interpretação da atualidade. Ao mesmo tempo, é ingênuo esperar que tais contribuições possam extrapolar a condição de "interpretação", "proposição" ou "projeto", com toda a carga de incerteza aí implicada. Mesmo esta ressalva não elimina, porém, que a contribuição prática das humanidades se veja confirmada pela influência rizomática que elas exercem sobre a interpretação do presente, a ação imediata e a imaginação do futuro, pouco importando se isso resulta da influência de grandes nomes - Le Corbusier, Keynes, Greenberg... - ou do trabalho localizado de agentes de menor fama, mas situados em posições de relativo poder e prestígio. É claro que isso tampouco deve ser motivo de comemoração irrestrita: muito da participação acadêmica no debate público se restringe à provisão da rationale que confere fundamento a práticas (artísticas, políticas, econômicas) adotadas por agentes e instituições diversas, reiterando hábitos normalizados de pensamento (de observação e juízo), sendo relativamente raras as proposições que, mantendo-se atentas à empiria e guardando distância dos consensos dominantes, combinam inovação e rigor analítico ao debaterem questões que mobilizam as paixões e tensionam o juízo.

Vejamos o caso recente de um trabalho deste tipo, de sucesso simultâneo na comunidade acadêmica e na mídia aberta (e configurando, portanto, um exemplo inverso do desinteresse que viemos comentando): trata-se de $O$ Capital no Século XXI, de Thomas Piketty. Uma característica daquela obra me interessa particularmente: tendo qualificado a 
economia como uma ciência social, ressaltando a dimensão histórica do fato econômico e o componente interpretativo inerente à sua análise - e assim resgatando o componente humanista da sua disciplina contra o seu monopólio pela matematização -, Piketty não recua do imperativo da cientifização: que ele tenha obtido tamanho sucesso, isso se deve à apresentação de resultados inovadores, empiricamente fundamentados pela análise sistemática de um grande volume de dados, e modelados sob um rigor metodológico que é trazido ao primeiro plano pelo debate minucioso das condições de interpretação de uma matéria que, como é o caso, não se oferece pronta para a análise. Piketty explicita que os seus dados são não apenas objeto de seleção, como também, nalguma medida, produto da própria interpretação, mas ao invés de derivar destas condições um lamento (nietzschiano, derridiano...) pela "impossibilidade" do conhecimento objetivo, ele responde com o imperativo (popperiano) da falseabilidade, incorporando à sua argumentação a discussão sobre os critérios de seleção e interpretação da matéria empírica e sobre os méritos e limitações dos métodos empregados. A defesa das suas escolhas a partir da exposição clara dos seus procedimentos e da manifestação de consciência dos seus limites - da sua necessária falibilidade - fortalece epistemologicamente os argumentos de Piketty, conferindo, ao final da exposição, grande credibilidade às suas propostas de ação: mas com que freqüência isso é visto na pesquisa realizada nas ciências humanas, no Brasil ou no exterior? Ao abordar o problema delicado da distribuição de renda, Piketty se afasta programaticamente do juízo moral e das clivagens ideológicas, que nem desaparecem de todo, nem tampouco podem servir como fundamento para a produção de conhecimento; consciente da finitude das suas próprias perspectivas, mas apoiado nas melhores evidências que ele se julga capaz de obter, um dos verbos que ele mais utilizada é "sugerir", palavra que salva-o da hybris implicada na utilização indiscriminada do verbo "ser": enquanto em Piketty lemos que "as evidências sugerem que", bem mais comum é ler-se que as coisas "são desse ou daquele jeito" e que para constatá-lo basta apreciar esses ou aqueles dados - cujos significados se tornam "autoevidentes" pela adequação seletiva, e tautológica, de certo paradigma teórico. Assim a paciência dá lugar à certeza rápida, a admissão da possibilidade de erro dá lugar à confusão entre indício e auto-evidência, e o debate fica suscetível ao imperativo moral, ao dogma coletivamente sancionado, à ideologia...

Por fim, quanto à terceira causa potencial do desinteresse - que os nossos modos de endereçamento aos nossos temas de eleição sejam parcialmente responsáveis pelo desinteresse manifestado por eles -, ela nos traz de volta às rotinas do ensino e da pesquisa. Preservados o ideal weberiano de ciência (pelo qual a academia permanece autônoma para estudar aquilo que ela considera digno de interesse) e o retraimento do pensamento (cuja lentidão deve ser preservada contra a rapidez que prevalece noutros domínios de produção), é importante entender que a autonomia de escolha aumenta a responsabilidade pela escolha. $\mathrm{O}$ humanista nem sempre se deixa formar pelas informações que ele recebe do mundo, interpretando-as à luz de modelos consensuais e convicções pessoais: ao invés de mantermonos em constante formação, colocando teorias e fatos em tensão recíproca para permitir que os modelos sejam transformados pelas informações, entre nós a empiria tem dificuldades de impor-se a convicções pessoais e paradigmas consensuais, que assumem um poder infinito de moldarem o real ao seu modo. No meu entender, este estado de coisas poda as capacidades imaginativas dos nossos alunos - para o pensamento especulativo, para a iniciativa profissional - de maneiras que ainda não foram plenamente compreendidas.

Como costuma ser o caso, as crenças mais perniciosas para certa coletividade são aquelas que fundamentam a sua auto-definição; nas humanidades, entre as mais contraproducentes estão a demonização da ciência, da tecnologia, do Capital e do Estado; a ideologização do juízo sob o apelo a valores naturalizados (e por isso raramente explicitados e debatidos); o estabelecimento da "crítica" à frente da pesquisa empírica como a nossa 
principal função social; o alinhamento a divisões ideológicas e ao debate partidário; a contradição entre a desconstrução de teorias concorrentes e a crença no realismo das teorias esposadas, predispondo o pesquisador à refutação imediata das evidências contrárias às suas previsões de rotina; a reverência à autoridade dos grandes nomes da história da arte e do pensamento. É claro que esses problemas não são unânimes - não quero construir um espantalho dos meus colegas de profissão -, mas não deve ser por acaso que a nossa pesquisa é caracterizada pela pouca cooperação e trabalho coletivo, que submergem sob pretensões à "autoria"; que carreiras inteiras sejam dedicadas à especialização no trabalho de um único autor ou paradigma teórico, cujo status como referência para a interpretação do real jamais é questionado; que propostas de consiliência com as ciências da natureza sejam objeto de raiva e ressentimento; que céticos que suspeitam das noções de "fato", "objetividade" e "progresso" do saber postulem a exatidão das suas "leituras" contra alternativas "ultrapassadas" ou "obsoletas"; que a reivindicação de prestígio social não problematize a origem e a sustentabilidade do financiamento das nossas atividades; que a filiação a "associações" e "grupos de pesquisa" desobrigue os seus integrantes do confronto com argumentos e evidências contrárias aos paradigmas internamente sancionados, levando a eventual discordância a girar em torno de pressupostos comuns; que quando estas circunstâncias se superpõem, a análise se mostre uma instância de confirmação de visões antecedentes à sua própria realização, eliminando-se de antemão a possibilidade da surpresa e da inovação. Mesmo que o leitor acredite que estes problemas não sejam a regra, vale perguntar em que medida e de que maneiras eles contribuem para reforçar o desinteresse pelas ciências humanas.

Um primeiro ponto a considerar é a tendência à endogenia. O universo da pesquisa é voltado para si mesmo: as suas rotinas e necessidades são geridas pelo setor público (universidades e agências de fomento), sendo desnecessário conquistar apoio externo (do empresariado e da sociedade civil). Se a isso somarmos a pouca oferta de trabalho no setor privado, raramente o pesquisador precisa cativar a atenção do não-especialista, que é irrelevante para as suas operações de rotina: muito mais importante é conquistar o apoio dos colegas, especialmente daqueles em posição de influência na atribuição de status e na alocação de recursos. Daí que não sejamos propriamente preparados para convencer a sociedade da nossa importância, mesmo que a nossa produção tenha potencial interesse conforme sugerem as obras de historiadores profissionais que abundam nas prateleiras das grandes livrarias. Em particular o mercado editorial se interessa por obras academicamente confiáveis, mas destinadas ao público leigo; o nosso sistema de recompensas não nos estimula, porém, a explorar este filão (um livro publicado recebe "pontuação" igual à de um artigo; o endereçamento ao público leigo não aumenta o status do pesquisador entre os pares). Isso poda a nossa visibilidade ao estimular a concentração intra-acadêmica, com a sua preferência por temas canônicos (aos quais atribuímos grande valor, mas pelos quais o público não necessariamente se interessa) e a sua inaptidão para a comunicação aberta (didatismo e coloquialismo são pouco valorizados, ou mesmo tolerados na "torre de marfim"). Nada a princípio favorece, pois, que saibamos nos comunicar com o público aberto a ponto de tornar interessante para ele os temas que nos interessam - que saibamos contagiá-lo com as nossas paixões. Preocupa-me especialmente que a preferência pelo estudo monográfico limite o espaço de questões transversais, i.e. dos temas como tais, à revelia do tratamento que eles recebem em autores específicos: ao passo que a "arte" tem um potencial permanente de interesse público, não se pode garantir o mesmo sobre a sua abordagem em Kant, Schopenhauer ou Heidegger, assim como o interesse pela literatura não garante o interesse por Lukàcs, Auerbach ou Antonio Candido. Ao discutirmos as coisas através do histórico de discussões sobre as coisas, aumentamos o peso da formação especializada, inflamos a importância dos modelos previamente sancionados pela academia e diminuímos o espaço para 
a interlocução imprevista; no ensino, aumenta a intimidação do jovem aprendiz e reduz-se o espaço para a fertilização da discussão pela dúvida ingênua.

Uma alternativa é trabalhar tópicos transversais, mesmo durante a interpretação de conteúdos específicos: ao lermos em sala de aula um romance, um drama ou um poema, trabalhar as teorias da narrativa, do drama ou da poesia; se o texto apresenta um conteúdo político, trabalhar a política nalgum grau de generalidade; da sua remissão à sociedade sincrônica e da sua condição de exemplar de certa literatura, trabalhar a consciência histórica dos alunos e jovens pesquisadores. Se isso parece óbvio, tudo bem: o que não podemos perder de vista é que a presença e influência social das nossas disciplinas só farão aumentar se as nossas práticas de docência e pesquisa levarem os objetos a transitarem pelo mundo, tocando universos familiares ao público imediato. Foi o que fez Stephen Greenblatt em $A$ virada: ao invés de encetar mais uma leitura cerrada do Tratado da Natureza de Lucrécio, ele discutiu as condições da sua escritura e da sua redescoberta no renascimento para refletir sobre a circulação do saber e os seus efeitos emancipatórios, fenômenos cuja extensão não se restringe à antiguidade ou à primeira modernidade - num exemplo de pesquisa que reconhece a sua distância em relação aos interesses medianos ao esforçar-se para aproximar-se do presente. E ao fazê-lo Greenblatt escreve numa linguagem clara, acessível, limpa de jargões e do peso da referência erudita - uma linguagem popular, mas não populista, como cabe ao ato de comunicação sinceramente interessado em extrapolar a sua inscrição acadêmica, preservando a sua credibilidade acadêmica. Quando essa vontade inexiste, o humanista não deveria, por uma questão de coerência, reclamar da pouca atenção que o seu trabalho recebe: enquanto as ciências da natureza tanto se preocupam em popularizar a ciência, nas humanidades não é incomum o depoimento do aluno que não entende aquilo que o seu próprio professor fala em sala de aula.

Não pode surpreender, pois, que o nosso ambiente tenha tão pouca vocação para capacitar os nossos alunos para atividades que nos sejam imprevistas. A defesa da autonomia da pesquisa não conflita com a ideia de que a formação oferecida pelos nossos cursos estimule empreendimentos de todo tipo, que possam levar os nossos alunos a se realizarem profissionalmente em áreas imprevistas, para onde eles levariam aquilo que aprenderam conosco (estimulando, talvez, alunos de outras áreas a nos procurarem para a fertilização de ideias nascidas noutros contextos). A autonomia da pesquisa pode conviver produtivamente com o risco implicado na abertura da nossa formação para o desenvolvimento de aptidões que nós mesmos seríamos incapazes de prever, assim reenergizando a presença das humanidades dentro e fora da universidade. Em geral, afora as áreas mais diretamente ligadas ao mercado a economia, a administração de empresas, a arquitetura e o urbanismo, a comunicação social, o direito... -, entre nós o ensino e a pesquisa pouco estimulam a imaginação prática; para além do estímulo a que os alunos repliquem o trabalho dos professores, tornando-se eles mesmos professores e pesquisadores, aquilo que oferecemos pouco estimula a imaginação de iniciativas diferentes daquilo que nós mesmos sabemos fazer. Mas o espaço da universidade pode fomentar e abrigar atividades de todo tipo: que outra instituição concentra tamanha quantidade de inteligência e energia jovem, tamanha circulação de informação qualificada, tamanha disponibilidade de tempo e espaço para a imaginação criadora? Que os alunos nos surpreendessem ao produzirem coisas alheias à nossa participação, apesar de possibilitadas pelo nosso ambiente: isso seria estimulante. Por enquanto, limitamo-nos a conceber os cursos de graduação como períodos de "formação" ou "aprendizado", e não como oportunidades para a conjugação entre a qualificação e o empreendimento. Esta limitação da imaginação criadora mantém intocado o status quo das nossas profissões, quando um dos nossos objetivos poderia ser a renovação do nosso status quo pela inserção dos nossos alunos em áreas de atuação que nós historicamente não ocupamos: se profissionais formados pelas humanidades passarem a ocupar posições tradicionalmente alheias a elas, seja lá quais elas forem, o nosso 
prestígio e influência aumentarão. Estaríamos levando a "torre de marfim" para fora de si mesma, com resultados de impossível previsão, mas que poderiam aumentar a procura pela nossa formação e reduzir o nosso pessimismo - a nossa sensação de crise. Confesso que eu sequer saberia por onde começar. Mas algum espaço deve haver para que os alunos, a partir da universidade mas olhando para fora dela, inventem e proponham, comprem, vendam e aluguem, corram riscos e pensem de maneira não-alinhada, e ao final avaliem por si mesmos os resultados disso tudo. $\mathrm{Na}$ área de letras, poderíamos estabelecer oficinas de escrita criativa: à diferença da arquitetura, da música e das belas-artes, os cursos de literatura não formam artistas, mas apenas apreciadores qualificados. Talvez a abertura desta possibilidade, dentro da série de interfaces que a escrita criativa estabelece com outros campos de atividade profissional, trouxesse alguma oxigenação à percepção do nosso futuro e do nosso pertencimento social - não tenho certeza, mas valeria a pena tentar.

Para além do que foi dito, um ponto merece destaque: vivemos num país cujos governantes, desgraçadamente, não buscam - ou francamente ignoram - o conhecimento produzido na universidade. Muito daquilo que fazemos teria outro destino caso nos fossem abertas possibilidades de ação no setor público, onde as nossas proposições poderiam alcançar os resultados práticos imaginados durante a pesquisa. Mas isso raramente acontece, e este é um lamento que nós - com a consciência tranqüila e em nome do interesse comum - temos todo o direito de fazer. No mais, e especialmente diante do crescimento recente do investimento na universidade pública, deveríamos pensar na arrumação da casa: ao pensar em temas como a ética, a moral, a política, a sociedade, a cultura, a comunicação, a linguagem, a sexualidade, o amor, a produção e a fruição da arte, os hábitos e as práticas sociais, as funções e as fundamentações do saber, e em disciplinas como a filosofia, a sociologia, a antropologia, a ciência política, os estudos literários, a lingüística, a psicologia e a história, tenho a impressão de que a crise diz respeito mais a essas disciplinas do que àqueles temas. Se a minha argumentação não resolve muita coisa, espero ao menos ter legitimado a ideia de que repensar as nossas instituições é um elemento importante para a compreensão do desinteresse manifestado pelo nosso trabalho. Isso implica alguma disposição ao risco - mas talvez nada mais além disso.

\section{REFERÊNCIAS}

GREENBLATT, Stephen. A virada - o nascimento do mundo moderno. São Paulo: Companhia das Letras, 2012.

PIKETTY, Thomas. O capital no século XXI. Rio de Janeiro: Intrínseca, 2014.

Recebido em: 09 de julho de 2015.

Aceito em: 21 de julho de 2015. 